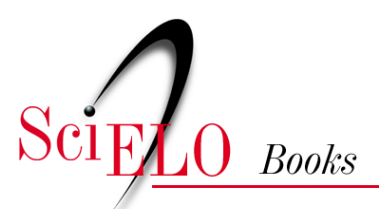

\title{
Capítulo 4 - Participação da Gestante Munduruku no Programa de Assistência Integral à Saúde da Mulher
}

\author{
Raquel Paiva Dias-Scopel
}

\section{SciELO Books / SciELO Livros / SciELO Libros}

DIAS-SCOPEL, R.P. Participação da Gestante Munduruku no Programa de Assistência Integral à Saúde da Mulher. In: A Cosmopolítica da gestação, do parto e do pós-parto: autoatenção e medicalização entre os índios Munduruku [online]. 2nd ed. rev. Rio de Janeiro: Editora FIOCRUZ, 2018, pp. 127-136. Saúde dos Povos Indígenas collection. ISBN: 978-65-5708-014-6.

https://doi.org/10.7476/9786557080146.0008.



All the contents of this work, except where otherwise noted, is licensed under a Creative Commons Attribution 4.0 International license.

Todo o conteúdo deste trabalho, exceto quando houver ressalva, é publicado sob a licença Creative Commons Atribição $\underline{4.0}$. 


\section{Participação da Gestante Munduruku no Programa de Assistência Integral à Saúde da Mulher}

As práticas de autoatenção relativas à gestação manejadas pelos Munduruku da Terra Indígena Kwatá-Laranjal (TIKL) até aqui apresentadas sintetizam o saber local sobre concepção, gestação e parto e diferem das noções de fisiologia e anatomia da biomedicina. Entretanto, isso não impedia que as mulheres Munduruku participassem dos programas voltados para a saúde da gestante, como o acompanhamento pré-natal, promovidos pelo serviço de saúde via Subsistema de Atenção à Saúde Indígena (Sasi), sob a gestão da Secretaria Especial de Saúde Indígena (Sesai), do Ministério da Saúde (MS). Desde a ampliação da cobertura da atenção primária no interior das terras indígenas brasileiras, inclusive na TIKL, uma das lacunas na execução das ações programáticas foi a questão logística, além da rotatividade dos profissionais da saúde, suas eventuais ausências e a falta de capacitação para atuar em um contexto interétnico (Dias-Scopel, 2005; Silva, 2011; Diehl, Dias-Scopel G Langdon, 2012). Neste capítulo apresentarei dados de observação participante realizada junto às mulheres da TIKL, às gestantes na Casa de Apoio à Saúde do Índio (Casai) e às Equipes Multiprofissionais de Saúde Indígena (EMSIs) que atuavam no Polo-Base Kwatá e no Polo-Base Laranjal, para que o leitor conheça os obstáculos para a oferta e o uso dos serviços de pré-natal às mulheres indígenas.

Antes, porém, convém explicar minimamente o que é o programa pré-natal. Assim procedendo, desnaturalizamos uma prática específica, relacionada a um determinado campo de saber-poder, permeada por tecnologias e histórias específicas, intervenções e formas de controles reguladores, micropoderes nas interações cotidianas e marcada pela racionalidade burocrática e capitalista. O pré-natal é um conjunto de práticas biomédicas voltadas para a redução da mortalidade maternoinfantil, iniciadas durante a gestação e finalizadas com consultas no pós-parto. No Brasil, trata-se de um programa gerido pela Área Técnica de Saúde da Mulher, sob a coordenação do Ministério de Saúde, responsável por formular a Política Nacional de Atenção Integral à Saúde da Mulher (PNAISM). As diretrizes e os princípios dessa política foram consolidados pelo MS em 2004. A atenção à saúde da mulher e adolescente indígena é mencionada no documento como um dos objetivos 
específicos da PNAISM no Brasil (Brasil, 2004a: 72). Nele, dados epidemiológicos sobre as condições de saúde da mulher indígena e os princípios de humanização e qualidade da atenção são considerados elementos indispensáveis para a melhoria dos níveis de resolutividade das ações de cobertura, assistência e promoção da saúde e daquelas voltadas para os problemas de maior incidência, entre os quais a mortalidade materna, cujas principais causas eram "a hipertensão arterial, as hemorragias, a infecção puerperal e o aborto, todas evitáveis" (Brasil, 2004b: 27). Acredita-se que 92\% das causas de mortalidade materna seriam evitáveis, e a atenção ao pré-natal teria importante papel a desempenhar nesse cenário (Brasil, 2004b: 26-30).

O Brasil segue as recomendações da Organização Mundial da Saúde (OMS) para a normatização das práticas de saúde da atenção ao pré-natal (Brasil, 2005). Em termos gerais, a atenção ao pré-natal consiste na promoção de ações para a prevenção e detecção de riscos para a saúde tanto da mulher gestante quanto do feto, nos períodos da gestação e do pós-parto, e na atenção à puérpera e ao recém-nascido, incluindo o tratamento de eventuais intercorrências. Isso é feito mediante uma série de procedimentos que incluem desde consultas médicas para a verificação do estado de saúde da gestante e para o acompanhamento do desenvolvimento do feto por meio de exames clínicos e laboratoriais e de imunização. A organização desses serviços é responsabilidade dos três níveis de gestão: federal, estadual e municipal. As ações da atenção ao pré-natal, segundo o manual técnico do MS Pré-Natal e Puerpério: atenção qualificada e humanizada (Brasil, 2005), incluem, prioritariamente: história clínica da gestante, exame físico e exames complementares.

A história clínica se fundamenta na anamnese e permite identificar desde dados socioeconômicos até a investigação de histórico de doenças familiares ou pessoais, entre outras questões (Brasil, 2005). Segundo esse manual técnico, o exame físico incluiria: determinação do peso e da altura; medida da pressão arterial; inspeção da pele e das mucosas; palpação da tireoide e de todo o pescoço, região cervical e axilar (pesquisa de nódulos ou outras anormalidades); ausculta cardiopulmonar; determinação da frequência cardíaca; exame do abdômen; exame dos membros inferiores; pesquisa de edema (face, tronco, membros); exame de mamas; palpação obstétrica e identificação da situação e apresentação fetal; medida da altura uterina; ausculta dos batimentos cardíacos fetais; inspeção dos genitais externos; inspeção das paredes vaginais; inspeção do conteúdo vaginal; inspeção do colo uterino; coleta de material para exame colpocitológico (preventivo de câncer), toque vaginal. Os exames complementares, ainda de acordo com o Manual, deveriam ser solicitados na primeira consulta e abrangeriam: dosagem de hemoglobina e hematócrito; grupo sanguíneo e fator Rh; sorologia para sífilis (VDRL); glicemia em jejum; exame sumário de urina; sorologia anti-HIV; sorologia para hepatite B; sorologia para toxoplasmose. É indicada também a solicitação de exames comple- 
mentares ainda na primeira consulta do pré-natal, conforme avaliação específica de cada caso. Gostaria de citar, por exemplo, o exame protoparasitológico, indicado "sobretudo para mulheres de baixa renda", e a ultrassonografia obstétrica. Entretanto, ainda que se admita o potencial da ultrassonografia obstétrica para "melhor determinação da idade gestacional, deteç̧ão precoce de gestações múltiplas e más formações fetais clinicamente não suspeitas", destaca-se que "a sua não realização não constitui omissão, nem diminui a qualidade do pré-natal" (Brasil, 2005: 29). Isso não se aplicaria aos casos em que se pretenda investigar alguma suspeita sobre o desenvolvimento da gestação e do feto no período tardio da gestação.

Pretende-se que esses procedimentos relativos ao pré-natal sejam uma referência para a organização da rede assistencial, a capacitação profissional e a normatização das práticas de saúde segundo princípios e diretrizes apresentados pelo MS brasileiro, inclusive para o atendimento das populações indígenas. Ainda segundo o documento normatizador, indica-se a realização de, ao menos, seis consultas nas ações de acompanhamento pré-natal e o registro das gestantes no cadastro nacional do Sistema de Acompanhamento do Programa de Humanização no Pré-Natal e Nascimento (SispreNatal).

Na TIKL, as ações do pré-natal se iniciavam nos polos-base localizados no interior das aldeias e se estendiam a unidades do Sistema Único de Saúde (SUS) na cidade de Nova Olinda do Norte para a realização de determinados exames de sangue, de fezes e de urina, por exemplo. Iara estava grávida de cinco meses quando foi encaminhada para Nova Olinda do Norte para realizar exames. Foi levada pelo motorista da EMSI, junto com outras gestantes que também tinham exames agendados. As gestantes Munduruku que acompanhei realizaram exames de urina e de sangue coletados na cidade de Nova Olinda do Norte. O transporte foi realizado pelos serviços do polo-base, que agendou dias específicos para levar todas as gestantes das aldeias. Note-se que o transporte foi feito pelo rio, com a lancha da EMSI, a partir da aldeia em que o polo-base estava localizado. As gestantes das demais aldeias foram transportadas até o polo-base com o auxílio do agente indígena de saúde (AIS), em geral com sua rabeta (canoa) de uso particular abastecida com recursos (considerados insuficientes) providos pelo Distrito Sanitário Especial Indígena (DSEI). O tempo de viagem até a aldeia onde se localizava o Polo-Base Kwatá podia chegar a dez horas, a depender da distância da aldeia, se o transporte fosse feito de rabeta. Assim, o deslocamento era difícil e envolvia riscos, fosse de rabeta ou de lancha, pois podia levar muitas horas, sem coletes salva-vidas e com exposição às intempéries, sobretudo sol intenso e chuva.

As gestantes foram para Nova Olinda do Norte e voltaram para a aldeia Kwatá no mesmo dia. Ao chegar em casa, Iara compartilhou comigo e com Ceci sua frustração com os exames realizados, pois "pensava que ia fazer ultrassom". Quando encerrei a pesquisa de campo, Iara estava com sete meses de gestação 
e não havia feito nenhuma ultrassonografia obstétrica. Embora ela tenha ficado frustrada por não tê-lo feito, vimos que esse exame não figura como prioridade nas ações básicas mínimas nos serviços de acompanhamento pré-natal, segundo recomendações do MS. Todavia, ela e as demais gestantes Munduruku não deixaram de fazer o exame por tal motivo, e sim porque o único aparelho de ultrassonografia na cidade de Nova Olinda do Norte estava quebrado durante o período de minha pesquisa de campo.

Dado o fato de estar grávida de três meses, quando retornei para a última etapa da pesquisa de campo eu também participei das ações do pré-natal no Polo-Base Kwatá. Embora já tivesse realizado duas consultas na cidade de Florianópolis, com um médico ginecologista e obstetra particular, e feito uma bateria de exames físicos e complementares, além de uma ultrassonografia obstétrica, só fui inscrita no SispreNatal quando da consulta no Polo-Base Kwatá. Lá ganhei um Cartão da Gestante, no qual foram registrados os resultados dos meus exames complementares previamente feitos e as informações sobre os exames físicos realizados nas demais consultas, bem como a orientação para cumprir ao menos seis consultas de "pré-natal". As ações do pré-natal realizadas no polo-base foram feitas pela enfermeira da EMSI e incluíam controle do peso, aferição da pressão, medição da altura uterina e palpação obstétrica. Além disso, na primeira consulta fiz também a imunização para influenza, a última dose da vacina para hepatite e a dose de reforço para tétano. Esses foram os procedimentos-padrão que toda gestante Munduruku recebeu ao acessar os serviços de acompanhamento pré-natal no Polo-Base Kwatá, incluindo ainda a suplementação com sulfato ferroso e, caso necessário, a disponibilização de antiácidos.

A enfermeira da EMSI lamentava o fato de que alguns exames recomendados pelo MS brasileiro, que inegavelmente contribuem para prevenir ou diminuir os riscos de uma complicação na gestação e no parto e para garantir o bem-estar da mãe e do bebê, não fossem realizados na cidade de Nova Olinda do Norte, devido à precariedade da infraestrutura e à inexistência de alguns serviços do SUS local. Na época da pesquisa de campo, por exemplo, as mulheres indígenas, e provavelmente toda a população usuária do SUS daquela cidade, passaram a gestação sem realizar a sorologia para as principais infecções congênitas (por exemplo, sífilis, HIV e hepatites B e C). A falta de realização desses exames é um indicador da baixa qualidade das ações de pré-natal (Brasil, 2004a: 28). Assim, evidencia-se uma oferta deficitária às mulheres indígenas, em razão não somente da inadequação dos serviços prestados pela EMSI e pelo DSEI-Manaus, mas também da precarização dos serviços prestados nas demais redes do SUS no nível municipal. Vale lembrar que em 2004 o MS brasileiro firmou o Pacto Nacional pela Redução da Mortalidade Materna e Neonatal, no qual a ampliação da oferta de exames laboratoriais e de tratamento para sífilis na gestação e sífilis congênita apareceram entre as ações a serem adotadas para 
a redução da mortalidade materna e neonatal e que o estado do Amazonas é uma das unidades federadas que aderiram a esse pacto (Brasil, 2004c).

A maior dificuldade dos profissionais da EMSI, durante a pesquisa de campo, para a promoção das ações do pré-natal foi garantir a realização de seis consultas às gestantes indígenas. No Polo-Base Laranjal, por exemplo, houve, no ano de 2010, o ingresso de três gestantes no SispreNatal com sete meses de gestação. Isso significa que a primeira consulta delas nos serviços do pré-natal só aconteceu no sétimo mês de gestação. E essas gestantes só acessaram os serviços do pré-natal porque a EMSI estava em campanha de vacinação na aldeia onde moravam. Aliás, as campanhas de vacinação, segundo os membros das EMSI, eram a oportunidade de eles se deslocarem do polo-base até as aldeias e, então, oferecer a atenção primária. Isso porque o deslocamento da EMSI para a atenção primária, incluindo o acompanhamento das gestantes no pré-natal, para as aldeias adstritas ao controle de cada polo-base no interior da TIKL envolvia recursos e logísticas cuja demanda não era suprida. Cito, ainda, a falta de infraestrutura adequada para a realização dos serviços de saúde e, principalmente, para acomodar os profissionais da EMSI nas demais aldeias. Esses eram pontos considerados relevantes pelos profissionais da EMSI e pelas lideranças indígenas que haviam incluído no plano de saúde local a demanda pela reforma dos polos-base já no ano de 2007. Os profissionais da EMSI até promoveram ações de atenção primária em condições improvisadas nos espaços de escolas e centros sociais da comunidade de cada aldeia, durante o período da pesquisa de campo. Todavia, exigir-lhes pernoitar por longo período, em média vinte dias, em condições adversas, muito diferentes daquelas em que se sentiam preparados, seguros e acostumados, não era uma questão que figurava no horizonte moral ou mesmo contratual, pois haviam sido contratados para atuar nos polos-base. Nesse contexto, a atuação dos AISs foi central em alguns momentos. Houve um dia em que a AIS da aldeia Tartaruguinha trouxe uma gestante até o Polo-Base Kwatá para fazer a primeira consulta do pré-natal. Da mesma forma, os AISs das aldeias Niterói, Fronteira e Malocão trouxeram também gestantes para fazer o acompanhamento pré-natal no Polo-Base Kwatá.

Não disponho de dados secundários que permitam afirmar quantas consultas de pré-natal foram realizadas durante o período do trabalho de campo ou mesmo quantas consultas cada gestante fez. No entanto, minha intenção não era avaliar a qualidade dos serviços de atenção ao pré-natal, o que exigiria metodologia específica, fosse a comparação entre indicadores de ações programadas e ações realizadas, fosse a avaliação do próprio usuário.

A observação participante me permitiu atestar que as articulações entre as formas de atenção biomédica e as formas de atenção indígenas, sejam xamânicas, de autoatenção, religiosas ou outras, foram realizadas pelos próprios indígenas no interior das práticas de autoatenção (Scopel, Dias-Scopel G Wiik, 2012; Scopel, 
2013). Foi o caso das mulheres gestantes Munduruku que realizaram o pré-natal no polo-base da aldeia Kwatá e na rede do SUS municipal, que também consultaram os especialistas indígenas, os pajés e as parteiras, para "pegar barriga". Ou, então, as mulheres mais velhas da família extensa com reconhecida expertise sobre banhos, "pegar barriga", "puxar a mãe do corpo" e outros saberes centrais à condução de uma gestação e um parto saudáveis, como uma dieta alimentar adequada, esforços para saciar o desejo ou para não se entregar ao "abalo de criança". Ou ainda, a fabricação de dádivas ao feto para garantir disposição e sucesso nas atividades diárias. Enfim, as mulheres indígenas articularam uma diversidade de formas indígenas de atenção à saúde e, especialmente aquelas que moravam nas aldeias onde os polos-base estavam localizados, também recorreram à diversidade de práticas biomédicas que constituem o acompanhamento pré-natal. Isso mesmo diante das dificuldades encontradas pela EMSI para promover as ações de cobertura do pré-natal na TIKL e apesar da precarização da rede do SUS na cidade de Nova Olinda do Norte.

A participação das mulheres Munduruku nas ações biomédicas de acompanhamento pré-natal era estimulada por diversos atores, entre eles a equipe de saúde, os AISs e as lideranças indígenas. Esses diversos atores sociais estavam a todo momento em reuniões da associação indígena ou da equipe de saúde, em campanhas de vacinação ou em dias de consulta médica, relembrando às mulheres indígenas as diversas exigências do MS para que a família mantivesse o recurso do Bolsa Família, "programa federal de transferência direta de renda a famílias em situação de pobreza e vulnerabilidade social" (Brasil, 2012). O estímulo vinha como contrapartida obrigatória das famílias beneficiárias do programa. Esses mesmos atores destacavam, sobretudo, a importância do comparecimento nas consultas de acompanhamento e da realização dos exames de pré-natal, caso atestada a gravidez, e o monitoramento do crescimento e vacinação das crianças. Além dessas ações, cumpre destacar que as famílias inscritas no programa ainda deveriam cumprir a exigência de retorno de consulta após o parto. ${ }^{58}$ De fato, a enfermeira do Polo-Base Kwatá relatara na reunião da Organização dos Povos Indígenas Munduruku e Sateré, realizada nos dias 28 e 29 de maio de 2011, um aumento de $100 \%$ na realização do exame de prevenção do câncer do colo do útero. Ela atribuiu a realização de cem exames coletados em vinte dias a uma nova exigência feita pelo Programa Bolsa Família. E afirmou, em público, que antes ninguém se dirigia a ela para realizar o exame. Outro dado sobre o trabalho da EMSI apresentado naquela reunião pela enfermeira foi o acompanhamento de trinta das 39 gestantes cadastradas pelo Polo-Base Kwatá no SispreNatal. Segundo ela, as dificuldades de deslocamento ou a ausência das mulheres na aldeia em dia de consulta médica ou em campanha de vacinação contribuíram para que nove gestantes ficassem sem qualquer acompanhamento pré-natal. 
Embora o MS tenha registrado, em 2004, alguns obstáculos para o alcance de uma qualidade mínima nos serviços de atenção ao pré-natal prestados na rede do SUS, foi identificada também uma queda na taxa de mortalidade materna entre 1999 e 2001 (Brasil, 2004b: 27). O MS atribui essa queda, bem como a da mortalidade infantil, ao aumento de consultas do pré-natal, incluindo a realização dos exames e da imunização recomendados, a partir do ano de 1997 (Brasil, 2004b: 28). Infelizmente, ainda não existe uma avaliação semelhante que considere a população indígena no Brasil. No entanto, encontramos, no relatório final do Inquérito Nacional de Saúde e Nutrição dos Povos Indígenas (Coimbra Jr. et al., 2009), informações relevantes sobre as condições de saúde das mulheres e crianças indígenas no país e alguns dados sobre o acompanhamento pré-natal, levantados em 2008 e 2009. No relatório consta que

88,6\% das mulheres referiram ter realizado pelo menos uma consulta de pré-natal com médico ou enfermeiro durante a gravidez do filho vivo mais novo com idade inferior a 60 meses (...). Porém, há importantes diferenças entre as macrorregiões. Enquanto no Norte e no Nordeste $72,4 \%$ e $86,4 \%$ das mulheres realizaram pelo menos uma consulta, respectivamente, no Centro-Oeste $(94,3 \%)$ e Sul/Sudeste $(97,5 \%)$ essas proporções foram superiores a 94\%, sendo essa superioridade estatisticamente significativa em relação ao Norte e Nordeste. (Coimbra Jr. et al., 2009: 179)

Consta também no relatório a média do número de consultas ao pré-natal realizadas pelas mulheres indígenas, a qual não atinge o número mínimo de seis consultas estabelecido pelo Programa de Humanização do Parto e Nascimento (Brasil, 2000):

A média do número de consultas pré-natais relativas à gravidez do filho vivo mais novo com idade inferior a 60 meses foi de 4,7 consultas por mulher (IC 95\%: 4,4-5,0) para o conjunto das macrorregiões, inferior ao número de consultas preconizado por mulher pelo Ministério da Saúde (...). Essa média foi mais baixa no Norte $(3,1$; IC 95\%: 4,4-5,0) e mais elevada no Centro-Oeste $(4,7$; IC 95\%: 4,2-5,2), Nordeste (5,3; IC 95\%: 5,0-5,6) e Sul/Sudeste (5,3; IC 95\%: 4,7-5,8), com diferença estatisticamente significativa entre essas macrorregiões e o Norte. (Coimbra Jr. et al., 2009: 182)

Outra fonte de dados relevantes sobre a atenção biomédica ao pré-natal é o trabalho Sateré-Mawé: retrato de um povo indígena (2005), que apresenta um diagnóstico sociodemográfico das condições de vida dessa população no estado do Amazonas. ${ }^{59}$ Isso porque na TIKL há uma aldeia habitada por índios Sateré-Mawé, contemplados no levantamento realizado por esse trabalho, adstrita ao Polo-Base Laranjal. Interessa-me destacar aqui os dados relativos à percepção das indíge- 
nas sobre o programa de atenção ao pré-natal. Das 381 indígenas residentes nas diversas aldeias Sateré-Mawé que haviam tido filho nos últimos 12 meses, 240 relataram não ter recebido qualquer atendimento biomédico referente à gestação no ano de 2003. Isso dá um total de 63\% de residentes em áreas indígenas que passaram a gestação sem atenção prestada pelos serviços de atenção primária ao pré-natal. Das 141 mulheres Sateré-Mawé que realizaram o acompanhamento pré-natal, "apenas nove (6,3\% do total) receberam um número de consultas próximo àquele recomendado (...) pelas normas do programa de saúde da mulher" (Teixeira, 2005: 81).

Os autores concluem: "os resultados obtidos indicam uma insuficiente cobertura pré-natal" (Teixeira, 2005: 82). Essa mesma conclusão se repetiu, como veremos a seguir, no relatório do Inquérito Nacional de Saúde e Nutrição dos Povos Indígenas (Coimbra Jr. et al., 2009).

Entre os dados do relatório do Inquérito Nacional de Saúde e Nutrição dos Povos Indígenas, cabe sublinhar a elevada prevalência de anemia nas mulheres grávidas da macrorregião Norte: em torno de 44,8\%, de uma amostragem de 142 mulheres (Coimbra Jr. et al., 2009: 145). Recapitulo esses dados porque informam, de modo geral, sobre as condições de saúde das mulheres indígenas no Brasil e, principalmente, porque na macrorregião Norte, onde se encontram os Munduruku da TIKL, foram encontrados os piores índices seja de condições de saúde, seja de cobertura e qualidade dos serviços biomédicos ofertados, referentes ao Programa de Humanização do Parto e Nascimento (Brasil, 2000).

Embora eu não tenha realizado um levantamento estatístico nem epidemiológico, os dados que obtive na observação participante apontam para a mesma direção das conclusões do Inquérito Nacional de Saúde e Nutrição dos Povos Indígenas (Coimbra Jr. et al., 2009). Em especial no que se refere à baixa qualidade do serviço de atenção ao pré-natal ofertada às gestantes Munduruku. Isso, de certa forma, corrobora os resultados apresentados no relatório final daquele inquérito, no qual a macrorregião Norte apresentou as menores proporções de "pedidos de exames, variando de 2,2\% para sorologia para rubéola a 32,6\%, para teste sorológico para sífilis (VDRL)". Todavia, como vimos anteriormente, as gestantes Munduruku não estavam fazendo tais exames à época da pesquisa de campo porque a rede municipal do SUS não os estaria realizando. Em síntese, os dados da pesquisa de campo na TIKL corroboram as conclusões apresentadas naquele inquérito: "Tendo em vista as ações preconizadas pelo Ministério da Saúde para uma atenção pré-natal qualificada (Ministério da Saúde, 2005), os resultados ora apresentados evidenciam condições menos satisfatórias do pré-natal na macrorregião Norte" (Coimbra Jr. et al., 2009: 188).

Entretanto, os desafios para ampliar a cobertura e a qualidade do Programa de Humanização do Parto e Nascimento (Brasil, 2000) no contexto de que os Munduruku da TIKL fazem parte não se limitavam às ações promovidas pela EMSI, no 
âmbito da atenção primária, ofertada pelo DSEI-Manaus. Naquele contexto, a rede do SUS na cidade de Nova Olinda do Norte, no nível secundário, também apresentava sua parcela de responsabilidade pela baixa qualidade das ações relativas ao acompanhamento pré-natal.

Por fim, gostaria de salientar outra razão da expectativa das gestantes Munduruku por realizar o pré-natal no Polo-Base Kwatá. O programa de acompanhamento pré-natal foi destacado pelos indígenas e por profissionais da saúde da EMSI como um pré-requisito para o recebimento do auxílio-maternidade. Em certo sentido, compreendo os motivos pelos quais essa ideia se sustentava, pois para requerer o auxílio-maternidade é preciso apresentar alguns documentos, como o atestado médico original ou a certidão de nascimento da criança. Tendo em vista que muitos partos foram domiciliares, sem a presença de um profissional biomédico, parece plausível supor que a posse do Cartão da Gestante serviria como prova, ao menos, da gestação. Todavia, essa é uma questão que merecerá uma futura investigação, capaz de contemplar os meios pelos quais as mulheres Munduruku têm usufruído do auxílio-maternidade e as dificuldades para requerê-lo. De antemão, sei apenas que era preciso se deslocar até a cidade de Itacoatiara, situada à margem esquerda do rio Solimões, de posse de um documento fornecido pela Fundação Nacional do Índio (Funai).

Em 2013, apresentei esses dados para alunos do curso de Licenciatura Intercultural Indígena, na Universidade Federal de Santa Catarina. Esses alunos me ajudaram a refletir sobre minha pesquisa. Um dos participantes, que era AIS, comentou que as mulheres Xokleng não realizavam mais o parto domiciliar; todas estariam fazendo apenas o parto hospitalar, pois assim obteriam o documento, atestado médico, para requererem o auxílio-maternidade com maior agilidade. Ele estava nos dizendo que uma questão de ordem legal, de escopo jurídico, estava condicionando a escolha do local do parto.

Entre os Munduruku da TIKL, como veremos a seguir, essa questão não apareceu como um fator importante na decisão de realizar o parto hospitalar. Entretanto, cumpre esclarecer que foi durante o período do acompanhamento pré-natal que os profissionais da saúde observaram a necessidade do parto hospitalar. Dessa forma, o sistema de saúde tem incentivado e estimulado as mulheres Munduruku a parir nos hospitais da cidade. Isso resultou em uma situação controversa, na qual a ideologia da medicalização do parto e uma crescente demanda, por parte dos profissionais da saúde e dos indígenas, pelo parto hospitalar em determinadas situações coexistia com um contexto de acesso restrito a tecnologias obstétricas, que não provia sequer um simples exame de sorologia para detecção da sífilis. Nesse contexto de baixa qualidade e cobertura das ações de acompanhamento pré-natal, a questão da cidadania desponta como um desafio continuamente vivenciado pelas mulheres indígenas no acesso aos serviços de saúde. 
58 Para maiores informações, ver a portaria interministerial n. 2.509, de 18 nov. 2004, que "dispõe sobre as atribuições e normas para a oferta e o monitoramento das ações de saúde relativas ao cumprimento das condicionalidades das famílias beneficiárias do Programa". Disponível em: < http://dtr2001.saude.gov.br/sas/PORTARIAS/Port2004/Gm/2509.htm>. Acessado em: 20 dez. 2013.

59 Resultado da parceria de diversas instituições sediadas no Amazonas, entre elas a Universidade Federal do Amazonas (Ufam), a Fundação Estadual de Política Indigenista do Amazonas, a Fundação Joaquim Nabuco, a Coordenação das Organizações Indígenas da Amazônia Brasileira e a Secretaria de Educação do Estado do Amazonas, em trabalho financiado pelo Fundo das Nações Unidas para a Infância e Fundo de População das Nações Unidas, sob a coordenação de Pery Teixeira, da Ufam. 